Iván Nyusztay

\title{
Tragic Delusion and Authentication
}

The present paper seeks to approach the problem of the tragic in Greek and Shakespearean drama through what will be considered as the fundamental determinant of tragic action: delusion. As it shall be argued, delusion has several modes of representation in tragedy, which though they may appear as extremely diverse, have the common denominator of leading the hero astray, of securing his constant being in the wrong. This deludedness is conceived of as such in tragic recognition, when individual reflection on delusion seems to take at least two distinct forms: imputation and internalization. The divine imputation of delusion, as Nietzsche among others claims, may merely serve to avert responsibility. The realization of individual guilt, or error, is accompanied by its attribution to divine delusion. He blunders because he is deluded. On the other hand, internalization indicates the acknowledgment of personal responsibility in misjudgment. Apart from the categorical imputation following a melodramatic impulse, recognition of delusion in pure tragedy encompasses a fusion of the apparently incompatible forms. It is this blend characteristic of heroic understanding that will concern us in expounding the problem of delusion. Our analysis, focused in this way, is hoped to foster the gradual crystallization of some major differences between what we call 'pure tragedy' and 'melodrama.'

Understanding the nature and scope of delusion also involves grasping its corollary: tragic authentication. It will be argued that tragic authentication is realized only at the expense of a preliminary assertion of an inauthentic miscon-

\footnotetext{
${ }^{1}$ The Genealogy of Morals, tr. Francis Golffing, Anchor Books, New York: Doubleday, 1956, p.228

${ }^{2}$ Emphasis should be laid on the some, since full definition of the genres would exceed the limits of the present essay.
} 
ception of identity. Acquired identity will merit the qualification authentic, once this initial misconception is conceived of as such, and thereby eliminated in purged reflection. This authentication is tragic because it cannot possibly be assumed without the preceding state of deludedness which inevitably leads to destruction.

The very term 'delusion,' already implies an encounter between two agents, the deluding and the deluded, the deceiving and the deceived. This polar division, as well as the identification of delusion, are both already based on an implicit differentiation between perspectives. In what follows we will indicate the generic significance of delusion by explicating the relevance of diverse perspectives.

\section{DUAL PERSPECTIVE AND TELEOLOGICAL CLASSIFICATION}

A dualistic perspective includes insider and outsider perspectives. The former is the prerogative of the hero, secondary characters and the Chorus. The latter is the privilege of the author-reader-audience triad. This dualistic sequestering of perspective is relevant in its mediatory role for the foregrounding of what will be termed 'differential teleology.' Differential teleology, characteristic of pure tragedy, harbours the opposition between the subjective telos of the hero immanent and constitutive of his action, and the objective telos of plot-structure. It may be argued that the hero's subjective teleological sequence of actions can hardly be isolated and identified without regard to the actions of other characters. Action is always interaction, and the interactive potential of the other characters is always already present in its commencement. However, the borders and the procedure of heroic action, similarly to the incurred reaction, are in terms of understanding, subject to an insider projection of subjective telos, or in other words, to a misleading prevalence of delusion. Delusion here is not merely a contingent attribute of insider perspective, but on the contrary, it appertains to its very nature. Deluded perspective becomes enlightened perspective in tragic recognition, when the whole past history of action is illuminated in accordance with the organizing principle of a new telos tragically incompatible with its subjective variant. The real direction of the action is revealed in retrospect, when the hero discovers at his own expense his true identity and fate. This retroactive constitution of the self in the light of the belated understanding of the objective telos is also the realization of a new arche. The final confirmation of differential teleology is contemporane- 
ous with the final recognition of true beginning. The acknowledgment and realization of difference is revelative of identity. Oedipus' act of self-blinding can be seen, in this sense, as the only act following from true knowledge of identity. The arche of the action of Oedipus as King in search for the cause of famine is very different from that of the action undertaken by the Oedipus of recognition. The acquisition of true arche is made possible only in tragic anagnorisis. The subjectively non-envisaged self-affirmation of objective telos is a means not only of breaking down insider aspiration, but also a means for revealing true identity, and consequently authenticating individual action. Oedipus' self-imposed suffering following from recognition seen in its double sense of delusion-authentication is tragic in Oedipus Tyrannus, and melodramatic in Oedipus at Colonos. In the latter, action and identity appear to be more or less independent from differential teleology, which consists in the externality of objective telos affirming itself against subjective understanding, and authenticating heroic action in recognition. Oedipus appears at Colonos as already authenticated, that is, if we approach the play in isolation, disregarding its mythical prehistory. What remains then to be justified is a tragically anachronistic self-validating move in plot-structure. This anachronism in plot-structure is the situating of the acquisition of true identity prior to the prescribed plot components of reversal and recognition.

The two Oedipus plays thus reveal the underlying structural discrepancy between tragedy and melodrama. It is relevant, however, to observe that differential teleology perseveres in the face of tragic recognition. The acknowledgment of delusion and the belated (non-anachronistic) understanding of true identity in recognition is not contemporaneous with a reconciliation with subjective and objective goals. In this retroactive self-constitution, the individual is eventually made to realize the contrary workings of objective telos. This individual understanding, however, consists in the mere acknowledgment of these incompatible, or parallel tendencies of an alien teleology, and not in the full recognition of objective telos itself. The division of perspectival goals in tragedy remains irreconcilable. In melodrama on the other hand, as in Eumenides of Aeschylus, the tragic discrepancy is substituted for a final justification of human goals. Here the complicity of divine will with human aspirations is the confirmation of the insider-heroic perspective, and the self-mitigation of objective telos. Orestes' matricide is in this sense justified by the divine command of Apollo, and is a process engendering a melodramatic culmination in the reconciliation of goals. This closure is brought about by the cadential moderation of the fate-Erinyes into the appeased Eumenides. 
It is not by chance that the latter goddesses are the local ruling deities in Oedipus at Colonos.

A similar compatibility of goals presents itself in the end of Sophocles' Pbiloctetes. The objective telos there is announced by the deus ex machina, and as a consequence, the hierarchical distance is abridged to secure a unification of goals. Heracles brings foreknowledge of and promise for the future, whereby the hero is willing to surrender his personal struggle for the subjective telos, and to follow the divine command towards elevation and harmony.

Teleological classification then, enhanced by the perspectival view, as outlined above, leaves us to reconsider the Hegelian concept of tragic reconciliation. Absence of generic differentiation within tragedies compels Hegel to merge an extreme diversity into a unified whole at the expense of having to discard a preestablished conceptual framework. His working concepts of situation, conflict, pathos and aspiration, applied to tragedies in general, prove untenable when forced onto particular plays like Eumenides, Oedipus at Colonos, and Philoctetes, which hardly endure subsumption. The problem of reconciliation now has to be recuperated under the light of the new findings in relation to differential teleology. For Hegel, reconciliation brings about the final appeasement of conflicting forces through the abrogation of one-sidedness. ${ }^{3}$ At the same time, however, reconciliation proves paradoxical in an overruling dialectic attesting to an over-emphasized perspective. From such an endlessly distanciated perspective the actuality of performance or reading would fail to achieve its cathartic effects. A reduced scope of perspectives, in the manner of the dualistic differentiation between insider and outsider perspectives, introduced in the present analysis, situates tragic reconciliation on a more focused plane. Following our argument, reconciliation of conflict in tragedy cannot be also the reconciliation of subjective and objective goals. In fact, what the hero is finally made to accept, is precisely the irreconcilability of necessarily divergent goals. The conflict is brought to a halt in tragic recognition, the contradiction is apparently resolved, but the open-endedness remains. Resolution in this sense is not concomitant with reconciliation from a teleological standpoint. The irreconcilability of discrepancy between goals is maintained until death, when the manifestation of mortality and finitude proves itself to be an integral part of a higher purpose. Finitude dramatized is the performed resignation to the irreconcilability between individual aspirations and the invincible power of tragedy. The objective telos, prerogative exclusively of this absolute divine power or fate, sub-

${ }^{3}$ Lectures on Fine Art, tr. T.M.Knox. Oxford: Clarendon, 1975, Vol. II. p. 487 
sumes and utilizes finitude itself in ways insider perspective can never account for. In tragedy, nevertheless, the notion of new arche, crystallizing in recognition, enables the hero to grasp his finitude as such, that is, as incapable of accounting for itself. The tragic experience framed by delusion-authentication has to be understood in this sense, namely that the miscarrying of deception, and its individual recognition, are essential preliminaries of an authentic internalization of finitude. True understanding of identity on the level of myth is the proper identification with finitude. It is this representation of a transformed consciousness of finitude that the actuality of performance brings about. The notion of finitude is shared by insider and outsider perspective, and serves as a point of identification, effectuating catharsis.

The concept of delusion then, serves as a structural axis of tragedy, around which the difference of objectives asserts itself. Due to its significance for the present teleological itinerary, it needs further consideration with regard to its manifest forms.

As a general rule, delusion is closely related to waywardness characterizing finitude. The finite conception of the telos of action is necessarily biased and wayward. This underlying ontological fallacy, a defect in being itself, is expressed in the one-sidedness of action. In Hegel's view, one-sidedness is activated through pathos, when circumstances and conditions are transformed into situation. The situation is established when the circumstances are no longer tenable, and harmony is shattered by collision. ${ }^{4}$ In tragedy this transformed state of affairs provides the grounds for the pathetic one-sidedness to activate itself. Its expressive representation in dramatic action is also the dramatization of finitude, and consequently the emplotment of delusion. Delusion appertaining to the nature of pathetic one-sidedness is evident in its inability to see itself as such. This is the tragic blindness of Antigone and of Creon alike, whose subjective waywardness in pursuing their respective goals is eliminated only in death. Creon's disproportionate punishment for ignoring the sacred duties of kinship is the irremediable loss of his wife and son. Through this loss however, the failure of one-sided aspirations and the waywardness of subjective telos are revealed, and Creon's identity authenticated.

Delusion, however, may be exercised by an external force, when an offended deity descends to mislead the over-confident mortal. The discrepancy between subjective and objective goals in these cases of deceiving divine intervention

${ }^{4}$ Ibid. p. 205 
is most conspicuous. These didactic forms of deception determine action in tragedies like Ajax, Hippolytus, The Madness of Heracles, Bacchanals, etc., and elicit the authentication of action and identity. Such extremes of direct interference with human aspirations may seem to be isolated instances of what Ricoeur calls the 'theology of blinding.' Situating these instances in the context of our speculations on delusion-deception, however, it may be argued that what appears as isolated, in fact, is a didactic form of representing the manipulative operation of objective teleology. In this sense it is delusion inherent in finitude that is evinced and exposed by the direct external interference.

The respective elicitations of authenticated action prove the inauthenticity of all preceding human endeavours. Both, at the same time, appear to be indispensable within an encompassing totality of tragic action. By the individual acknowledgment of delusion, inauthenticity becomes a necessary prerequisite for achieving true identity. This authentic knowledge of oneself is precisely the integration of inauthenticity as inherent in one's finitude itself. The acquisition of this tragic wisdom takes place in the new arche of action, in recognition, when deludedness is finally overcome. This stage of overcoming is simultaneously the culmination of tragic action, as in Oedipus Tyrannus, since, as argued above, when made the basis and starting point of action, as in Oedipus at Colonos, it appears void of the required preconditions for tragic wisdom, and becomes melodramatic. The suicide of Ajax, the self-blinding of Oedipus, the self-sacrifice of Makaria, and the various forms of consummating individual suffering ${ }^{5}$ are all instances of authentic action, dictates of tragic wisdom.

The close interdependence of delusion-deception and authentication as illustrated above has been grasped as such through the preliminary stabilization of what we called dual perspective and differential teleology. The necessary waywardness of the subjective telos was claimed to be revealed in the recognition of the contrary workings of the objective telos. The stress was laid on the contrary workings, to highlight the persevering irreconcilability of goals. The individual realization of irreconcilability itself was presented as a new understanding of tragic reconciliation. What seemed, however, a substantial precondition for such a conclusion, was the immovability and invincibility of the objective telos or fate. The identification of the ultimate purpose of fate is the exclusive privilege of the representatives of outsider perspective versed in mythology.

\footnotetext{
${ }^{5}$ For the element of suffering as prescribed by Aristotle, cf. Poetics $1452 \mathrm{~b} 9$
} 
Fate from a teleological point of view may be equated therefore with the objective telos, the preserver of the sound totality of myth. It needs to be added at the same time, that not all the so-called traditional stories of mythology qualify as raw material for tragedy. According to Aristotle's restrictions, the plot (muthos) should recount a transformation from prosperity to adversity, metabole ex eutychias eis dustychian (Poetics 1453a14). It is most tragic, tragicotatos, when the plays end in adversity, eis dustychian teleutosin (1453a26). Euripides here is given preference as exemplary dramatist, who despite his other defects, is the most tragic of poets, precisely for his frequent and thorough exploitation of unhappy endings. The role of muthos as telos of tragedy and the rule of adverse cadence are given prominence in Poetics, and linked in this synthetic statement: the end is adversity.

In tragedy then, action, determined by differential teleology, is also characterized by a pre-subordination to an unfortunate conclusion. The sound totality of myth safeguarded by fate and objective telos is, consequently, to be understood to contain the necessary pre-subordination to adverse cadence in plot construction. It is this essential restriction, the emphasis on unhappy ending, that, along with other elements discussed, distinguish pure tragedy from melodrama.

\section{MELODRAMATIC POTENTIAL IN SHAKESPEARE}

The recourse to differential teleology and adverse cadence to secure the isolation of the tragic from melodramatic proves feasible also in Shakespearean drama. There we find the same mechanism of delusion-authentication expose itself for perspectival scrutiny. We must take into account however, that it is problematic to label any Shakespearean play melodrama, with the possible exception of Titus Andronicus to which we shall return later. The focus of the following brief survey therefore will be restricted to some indications of melodramatic potential inherent in the tragedies. The pinpointing of this potential may serve to illumine the architectonics of the genre as a whole.

Instead of the typical commencement of Greek tragedies, which presents a hero predestined to delusion, Shakespearean figures like Richard III or Lady Macbeth appear on the stage as endowed with apparently self-assured identity. The self-confidence and commitment to individual purpose implies an anachronistically acquired selfhood. This assuredness is made explicit in Richard's prologue, "I am determined to prove a villain / And hate the idle pleasures of these days" 
(I.ii.30-1). ${ }^{6}$ This programmatic deliberation is based on a confessed identity, "I am subtle, false, and treacherous" (37). Both didactic articulations of aspiration and identity run contrary to Aristotle's appertaining requirements. The hero, according to the Poetics, should not fall into adversity through evil and depravity (dia kakian kai mochterian), but through some kind of error (hamartia) (1453a8-9).

At this point in Richard III there is nothing to indicate that Richard's selfidentity is based on an erroneous judgment of himself. It is only in recognition, enhanced by the ghosts of the murdered victims, that the error of misconception of identity is confirmed in the words of conscience:

O coward conscience, how dost thou afflict me! [...]

What do I fear? Myself? There's none else by;

Richard loves Richard, that is I and I.

Is there a murderer here? No. Yes, I am!

Then fly. What, from myself? Great reason why,

Lest I revenge? What, myself upon myself?

(V.iii.180-7)

The former self and its misdirected actions are here split, "I rather hate myself for the hateful deeds committed by myself" (190-1). The character appears as divided within itself, which in Richard's case, is also the surfacing of personal value. In recognition, internal division seems to reveal the deludedness of the previously maintained self-identity, and authenticates the character through the removal of delusion. This removal of delusion preserving false identity is constitutive of a new beginning, an authentic identity which sees itself as divided, and which as such surfaces immanent virtue. Personal excellence and virtue revealed in dividedness cancel an impending melodramatic closure through their final annihilation in death. In other words, we may argue that it is the loss of authentically surfaced value which creates tragic completion.

Misjudgment of personal identity confirmed in retrospect is an inevitable failure, the acknowledgment of which brings tragic wisdom. Tragic wisdom is authenticated self-knowledge, which according to the generic precepts of tragedy, is concomitant with extensive suffering and death.

We find similar congruence of ceasing delusion and acquired wisdom in Macbeth. In her role of proximate instigator Lady Macbeth appears as a domesti-

\footnotetext{
${ }^{6}$ All references to Shakespearean plays are to the Arden editions
} 
cated witch, fully intent on exploiting the rising opportunity of regicide. The fervour of deliberation itself implies an already unsexed, or rather sexless ${ }^{7}$ nature, which is problematic with regard to effectuating instigation. Lady Macbeth unsexed could not possibly achieve influence on a puzzled husband.

The assumed one-dimensional stabilization of identity is expressly melodramatic in the defiance of human qualities: "no compunctious visitings of Nature / Shake my fell purpose" (I.v.45). It can hardly be doubted that after this determination of identity and purpose, reminiscent of that of Richard's, it is precisely and exclusively the compunctious visitings of Nature that can secure tragic fulfillment. In other words, this purposive deliberation has to be redefined as delusion on the tragic schema, and proved anachronistic.

It is the scene of recognition in somnambulism that identity is confronted with itself. The futile attempt to eliminate the effects of the deed, "will these hands ne'er be clean?" (V.i.41) shows the uncontrollable overpoweredness of identity by action. The dividedness of the character is concomitant with the realization of irredeemability; "What's done cannot be undone" (64). The scene of indelible defilement contextualizes the tragic recognition of true identity. The despair foreshadowing the authenticated act of suicide is the unconscious counterpart of Richard's sober conclusion, "I shall despair" (V.iii.201).

A more didactic mode of delusion is, of course, that of Macbeth himself. The prophecy of the witches, which seemingly vouchsafes protection for the hero, engenders overconfidence and pride in him. This pride is manifest in the forgetting of finitude in the supernaturally encouraged mastering of the future. ${ }^{8}$ Finitude at the same time, asserts itself in the paradox of disbelief: Macbeth cannot conceive of the supernatural mobility of Birnam wood, and the possibility of being murdered by a not-of-woman-born, though he never doubts the prophesying supernatural forces. It is only when the unexpected turns reality, the state of delusion is transformed into the state of dividedness, that Macbeth is confronted with the contrary workings of fate, "And be these juggling fiends no more believ'd, / That palter with us in a double sense" (V.viii.19-20). Equivocality pres-

${ }^{7}$ She will soon confirm her sexlessness in the meticulous arrangement of execution, when she "dares do more than may become a man," and becomes "none." "None" here indicates superhuman; or devilish, cf. Arden fn. to I.vii.47. ed. Kenneth Muir, London and New York: Routledge, 1994

${ }^{8} \mathrm{Cf}$. Macbeth's offhand reaction to the servant's announcement of the approaching English force, "Where gott'st thou that goose look? [...] Go, prick thy face, and over-red thy fear, / Thou lily-liver'd boy. What soldiers, patch?” (V.iii.12,14-15). 
ents itself here to reinforce the fair-is-foul-foul-is-fair pattern, ${ }^{9}$ and to confirm the non-viable aspirations of self-idolizing finitude. In didactic representations of delusion, however, this inherent double sense is made conspicuous from the very beginning of action, through the duplication of perspectives. The first appearance of the chthonic ministers of fate, and their encounter with Macbeth already establish an incompatible divergence of visions, which only outsider perspective can account for. The fair-is-foul-foul-is-fair pattern is the foundation of a superhuman truth, to which the individual can only unconsciously consent: "So foul and fair a day I have not seen" (I.iii.38). ${ }^{10}$ This unconscious confirmation of the predominance of a superior organizing principle becomes conscious in recognition through reflection on the double sense.

Apart from Macbeth we hardly find didactic representations of delusion in Shakespeare. It may be argued however, that the ghost of Hamlet predestines with a delusive command. It is not deluding because the ghost "may be a devil" who "abuses me to damn me" (II.ii.595,599), since tragic delusion, as expounded above, cannot tolerate its anachronistic revelation. What never presents itself as an impossibility to Hamlet in his reflecting procrastination is the demand of private revenge. The King is never alone, publicity serves to camouflage privacy in pretence. The only occasion for private revenge is Claudius' attempt at prayer, when considerations of heavenly afterlife prevent the regicide. The scene of prayer then, is significant for at least two reasons.

Firstly, Hamlet's task reveals itself as an impasse, the impossibility of private revenge. The impasse is asserted in the overmagnification of the task on the one hand, and in a mistake on the other. The exaggerated concentration on Claudius' perdition points to the inevitably exaggerated character of the command itself: revenge by definition transcends privacy. However, at the same time, Hamlet is mistaken in postulating salvation for the King, since the prayer is unsuccessful, "words without thoughts never to heaven go" (III.iii.98).

Secondly, the contrition scene averts the melodramatic potential inherent in Claudius' public role-play. The latter involves the Machiavellistic machinations of pretence, which characterize Claudius' initial appearance. The speech of the

\footnotetext{
${ }^{9}$ For the constantly recurring tone of equivocality let us recall Macduff's often neglected though crucial statement following Malcolm's deliberately puzzling self-criticism, "Such welcome and unwelcome things at once, / 'Tis hard to reconcile" (IV.iii.138-9).

${ }^{10} \mathrm{The}$ verbal resonance of superhuman truth in Macbeth's first sentence already shows the necessary subordination of heroic aspiration to predicting forces.
} 
declaration of power presents a rhetorical mingling of public affairs with personal interests. Matters of privacy claim general appreciation and justification through their seemingly casual insertion between the public remembrance of mourning and foreign policy (remembrance of "our dear brother's death" and the territorial claims of young Fortinbras). The stabilization of institutionalized identity is in its inception grounded on role-play and appearance. The apparent perfection of appearance defines the character until recognition, when disguise succumbs to dividedness, intent to guilt, "My stronger guilt defeats my strong intent" (III.iii.40).

The recognition of indelible defilement in the words, "Is there not rain enough in the sweet heavens / To wash it ${ }^{11}$ white as snow?" (45-6) recalls Lady Macbeth's futile washing of her stained hands. ${ }^{12}$ The common tone of despair is complemented with an acquired notion of irredeemability in the experience of an excess of blood stains for Lady Macbeth, and of binding present possessions for Claudius, "I am still possess'd / Of those effects for which I did the murder" (54). ${ }^{13}$

Tragic recognition then, as argued above, involves the transformation of false identity to internal conflict which engenders dividedness and the simultaneous surfacing of human value. Without a proportionate discovery of an object of appreciation in the character, the impending human loss would enhance a melodramatic closure. At the same time, proportion needs further consideration as a generic determinant in relation to delusion. The absence of transformation in Iago's character does not make Othello melodramatic, while Aaron's rigid immovability seems to justify the isolation of Titus Andronicus as Shakespeare's version of melodrama. The emphasized inflexibility of the deceiver-villain on the tragic schema has to be proportionate with the dividedness produced in the deceived victim. Iago's rigidity, in this sense, serves to increase the dividedness in Othello, and to prepare a tragic downfall. Aaron's immovability ${ }^{14}$ on the contrary, is disproportionately magnified, since there appears to be no countermovement in Titus' heroic consciousness.

\footnotetext{
${ }^{11}$ i.e. the "cursed hand" (43).

${ }^{12} \mathrm{Cf}$. "All the perfumes of Arabia will not sweeten this little hand" (V.i.47-8).

${ }^{13}$ See also Lady Macbeth's "Whats done cannot be undone" (V.i.64), and Claudius' "My fault is past" (III.iii.51).

${ }^{14}$ Consider, "I am no baby, I, that with base prayers / I should repent the evils I have done; / Ten thousand worse than ever yet I did / Would I perform, if I might have my will. / If one good deed in all my life I did, / I do repent it from my very soul" (V.iii.185-190).
} 
These variations of intersubjective delusion present a situation when an opposing aspiration gains predominance temporarily. In such cases however, these deceivers, observed from an outsider perspective, prove merely mediators in the unfolding of a more profound existential experience of delusion, when the deceived seems to enlarge the actuality of delusion to a transformed understanding of being. 